\title{
Article \\ Modelling of the Ability of a Mixed Renewable Generation Electricity System with Storage to Meet Consumer Demand
}

\author{
Constance Crozier ${ }^{1}$, Christopher Quarton ${ }^{2}$, Noramalina Mansor ${ }^{2}$, Dario Pagnano ${ }^{2}$ and Ian Llewellyn ${ }^{2, *}$ \\ 1 Department of Civil, Environmental \& Architectural Engineering, University of Colorado, \\ Boulder, CO 80309, USA; Constance.Crozier@colorado.edu \\ 2 Directorate of Science, Innovation, Climate and Energy, Department for Business, Energy and Industrial \\ Strategy, London SW1H 0ET, UK; Chris.Quarton@beis.gov.uk (C.Q.); Noramalina.Mansor@beis.gov.uk (N.M.); \\ dario.pagnano@gmail.com (D.P.) \\ * Correspondence: ian.llewellyn@beis.gov.uk
}

check for

updates

Citation: Crozier, C.; Quarton, C.;

Mansor, N.; Pagnano, D.; Llewellyn, I. Modelling of the Ability of a Mixed Renewable Generation Electricity System with Storage to Meet Consumer Demand. Electricity 2022, 3,16-32. https://doi.org/10.3390/ electricity 3010002

Academic Editor: Poria Hasanpor Divshali

Received: 9 November 2021 Accepted: 30 December 2021 Published: 6 January 2022

Publisher's Note: MDPI stays neutral with regard to jurisdictional claims in published maps and institutional affiliations.

Copyright: (C) 2022 by the authors. Licensee MDPI, Basel, Switzerland. This article is an open access article distributed under the terms and conditions of the Creative Commons Attribution (CC BY) license (https:// creativecommons.org/licenses/by/ $4.0 /)$.

\begin{abstract}
In this paper, we explore how effectively renewable generation can be used to meet a country's electricity demands. We consider a range of different generation mixes and capacities, as well as the use of energy storage. First, we introduce a new open-source model that uses hourly wind speed and solar irradiance data to estimate the output of a renewable electricity generator at a specific location. Then, we construct a case study of the Great Britain (GB) electricity system as an example using historic hourly demand and weather data. Three specific sources of renewable generation are considered: offshore wind, onshore wind, and solar PV. Li-ion batteries are considered as the form of electricity storage. We demonstrate that the ability of a renewables-based electricity system to meet expected demand profiles can be increased by optimising the ratio of onshore wind, offshore wind and solar PV. Additionally, we show how including Li-ion battery storage can reduce overall generation needs, therefore lowering system costs. For the GB system, we explore how the residual load that would need to be met with other forms of flexibility, such as dispatchable generation sources or demand-side response, varies for different ratios of renewable generation and storage.
\end{abstract}

Keywords: intermittency; wind energy; solar PV; Li-ion; storage

\section{Introduction}

Many countries, including the United Kingdom (UK), are moving towards net carbon dioxide neutrality by 2050, where any emissions of man-made $\mathrm{CO}_{2}$ are compensated for by negative emissions from greenhouse gas removal technologies. Since negative emission technologies are expensive and of limited capacity, most areas of economic production, including electricity generation, will have to be largely non-emitting before 2050 to meet this goal [1]. At the same time, increased use of electricity in transport and heating to displace existing fossil fuel alternatives is increasing demand for electricity generation and transmission, thus requiring more low-carbon electricity to be produced in a way that is balanced with consumer demand $[2,3]$.

Although difficult, the goal of a $100 \%$ zero-carbon electricity system is possible and may lead to lower overall system cost than fossil fuel generation due to rapid decreases in renewable generation prices [4]. One analysis presents plans for 139 countries to transition to $100 \%$ clean and renewable energy by 2050 [5] and several studies [6-8] have produced detailed pathways in different countries for renewable energy to meet $100 \%$ of electricity demand. In the UK, the Government has recently indicated that they aim to achieve a zero-carbon electricity system by 2035 , which is in line with advice from the UK Climate Change Committee $[9,10]$.

There are several problems in transiting a predominantly dispatch led fossil fuel generation network to one dependent on renewable generation: 
- Many forms of renewable generation are intermittent and non-dispatchable; only some forms, such as biomass generation and certain types of hydroelectric schemes, can be dispatched by a central controller in much the same way as fossil fuel generation. Various kinds of renewables have different capacities for generation in the seasons as local weather conditions vary. A much better control strategy is needed to control a renewables based network [11].

- It is not possible to match generation with rapid changes in demand without the careful use of other ancillary services procured by the network operator. These services include the use of electricity storage in the network, the smart grid enabling demand side response services and the use of interconnections to other networks to provide balancing services over a wider area [12].

- Increased contribution of convertor fed renewable generation will lead to a lowering of system inertia compared to fossil fuel rotating generation. This can be overcome by incorporating faster control in the network to reduce inertia demands and potentially by the use of synthetic inertia from renewables and energy storage systems. A review of this issues can be found here [13].

- Lower load factors from renewable generation compared to fossil fuel generation lead to system assets such as transmission networks being under-utilised. This can be mitigated by increasing load factors from renewables by technology improvements. For example, the latest large offshore wind turbines can have load factors of $60 \%$ and improvements in solar PV technologies are doubling the energy delivered from a solar panel of a certain size $[14,15]$.

This paper looks at the requirements to balance generation and load in a UK based fully renewable electricity generation system using a mixture of both renewables (solar PV, onshore wind, offshore wind) and electricity storage (lithium ion based battery storage). It concentrates on the optimisation of the type of renewables to give diversity to the generation mix and the storage in the network to allow operators to balance demand over both short and extended periods.

To model the situation where both generation from renewables and demand are correlated, we introduce a novel model: Storage and Cost Optimization of Renewable Electricity Systems (SCORES). SCORES uses real weather data with geographic coverage of the whole of GB from the past 25 years at one-hour intervals to generate a realistic electricity generation profile from a range of geographically distributed renewable assets. SCORES uniquely also includes realistic engineering models of types of electricity generation and storage to explore the effect of different mixes on the availability of electrical power. The profiles generated are then compared to a one-hour resolution demand model to get a reliability metric of the system for meeting overall consumer demand.

This model allows us to be uniquely able to answer the question 'what percentage of time can demand be met with a mix of renewables and storage at certain deployment levels?'. Unlike other models that take advantage of high-resolution historic weather data, such as the Renewables Ninja platform $[16,17]$, SCORES is sensitive to the type of renewables deployed and even to technologies now being innovated (for example, the proposed engineering characteristics of the $>15 \mathrm{MW}$ offshore turbines now under development), the location of assets deployed, and the type of storage used in the network. Furthermore, unlike other energy system models such as UK-TIMES [18] and IWES [19], SCORES uses historic hourly weather data and, therefore, includes a much more realistic and high-resolution representation of the variations in renewable energy generation.

The novel contributions of this paper can be summarised as follows: First, that the proposed model captures the parameters of various generation and storage technologies, even those that are not yet commercially deployed. Second, that the developed framework incorporates the geographic variation in renewables output and allows the generation output at a new site to be modelled. Third, that, using a case study of the GB system, we investigate the percentage of consumer load that could be met with various combinations of generation and storage. 
The model is being published as open source alongside this paper, allowing others to perform their own case studies. In future papers we will extend this to other forms of longer-term storage (thermal, hydro, power-to-gas, compressed air, liquid air) and less common forms of renewables to see what effect these future technologies will have in meeting 2050 targets. In this paper, we optimise to find the best match of generation to demand, future papers will also look at optimising the cost of deploying these solutions.

\section{Materials and Methods}

The SCORES model was developed for this study to explore the relationships between intermittent renewable electricity generators, electricity demands, and storage technologies. The model is outlined in the following subsections.

\subsection{Model Overview}

The SCORES model consists of several separate sub-models, which can be combined to carry out simulations or optimisations of a whole electricity system. A schematic overview of the model is shown in Figure 1.

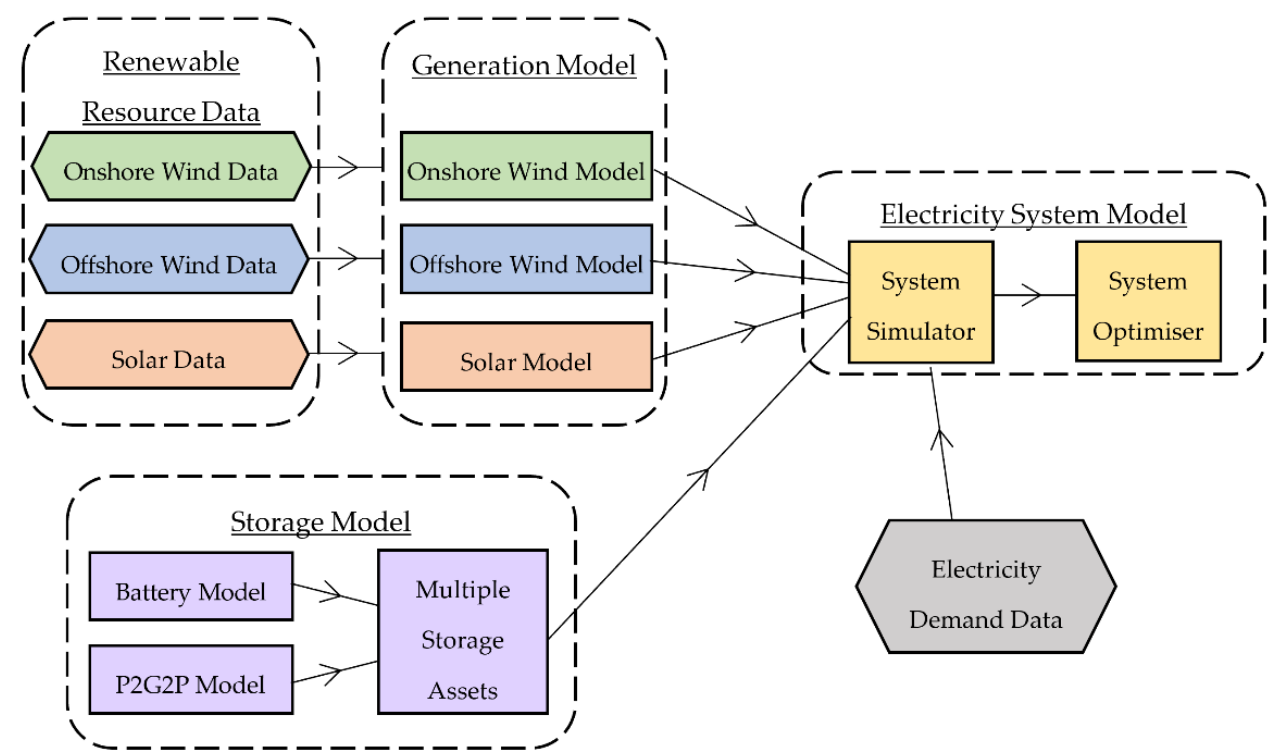

Figure 1. Schematic representation of SCORES model. The "Generation Model" makes use of renewable resource data, and contains sub-models representing onshore wind, offshore wind and solar. A separate "Storage Model" has sub-models representing different storage technologies, and a "Multiple Storage Assets" Model" to manage the interactions between these technologies. The "Electricity System Model" makes use of the Generation Model, the Storage Model, and demand data to carry out simulations or optimisations of the overall electricity system.

The model makes use of high-resolution renewable energy resource data, shown in Figure 1 in the dashed box named "Renewable Resource Data". These data include historic hourly wind speeds and solar irradiance data for a grid of datapoints across Great Britain and its territorial waters. More information is provided in Section 2.2.

The "Generation Model" makes use of the Renewable Resource Data via technology specific sub-models for onshore wind, offshore wind and solar photovoltaics (PV). These sub-models include the technological parameters and relationships required to convert the hourly resource data into hourly generation profiles. More information on these sub-models is provided in Sections 2.3.1 and 2.3.2. The Generation Model is a standalone model, which can be used to calculate various results, such as annual load factors for different technology types or locations.

The "Storage Model" is a separate model that is used to represent electricity storage assets. This model contains the necessary constraints to manage the charging and discharging 
of storage technologies. Sub-models are used to represent different storage technologies, such as batteries or power-to-gas-to-power (P2G2P). Additionally, the storage model contains a "Multiple Storage Assets" function, which manages the relationship between different storage technology types, for example, determining which technology should be charged or discharged first. The Storage Model is described in detail in Section 2.4.

The Storage Model interfaces with the Generation Model, via the "Electricity System Model". The key function of the Electricity System Model is to compare the electricity generation profiles generated in the Generation Model with pre-determined electricity demand data, generating an hourly profile of electricity "surplus" (when generation exceeds demand) or "deficit" (when demand exceeds generation). Based on this profile, operation of an electricity system can be simulated over one or more years. As described in detail in Section 2.4, the "surplus" profile generated by the Electricity System Model is also used by the Storage Model in the simulation of storage operation.

The Electricity System Model is still in development, but is intended to include various other functions to provide overall system analysis. This will include modelling technology costs, and a system optimiser, which will seek the combination of generation and storage installed capacities that achieves the lowest overall system cost while still meeting required reliability levels. Details of this will be published in future work.

\subsection{Renewable Resource Data}

The SCORES model can make use of global reanalysis models such as the NASA Modern-Era Retrospective analysis for Research and Applications (MERRA-2) [20]. This has a spatial resolution of $50 \mathrm{~km}$ and global coverage, meaning that SCORES could be applied to any country or energy system in the world.

In this study, MERRA-2 is used to provide the onshore wind speed data. For greater resolution and accuracy in the context of Great Britain, sources from the UK Met Office are used for offshore wind speeds and solar irradiance. The offshore wind speed data are sourced from the Met Office's Virtual Met Mast (VMM) dataset [21]. The VMM utilises data from Met Office regional-scale numerical weather prediction (NWP) models to which adjustments are applied to account for local complexity such as the effects of local topography and near-coast effect. It covers a period of over 34 years at $150 \mathrm{~m}$ height for 512 sites in regular spaced grids $(30 \mathrm{~km} \times 30 \mathrm{~km})$ across Great Britain's offshore sea water. The solar irradiance data are sourced from Met Office datasets from 80 observation centres across Great Britain, covering up to 10 years [22].

Where there is not a data point at the specific location being simulated, a spatial interpolation is performed. The three closest data points are located and linearly weighted by their distance from the simulation point, such that the closest point is most strongly represented.

\subsection{Generation Model}

SCORES' Generation Model contains a series of technology-specific sub-models. Each sub-model includes the relationships and parameters necessary to convert the hourly renewable resource data into power generation profiles. The sub-models are described in the following sub-sections.

\subsubsection{Offshore Wind Model and Onshore Wind Model}

Both the Offshore Wind Model and Onshore Wind Model use the same approach to convert wind speed data to power output. The only differences between the models are the wind speed data used and the turbine technology parameters.

To calculate the hourly power output profile, first the wind speeds in the renewable resource data are adjusted to account for differences in height between the wind turbine hub height $h$ and the height at which the wind speed data were measured, $h_{r e f}$ :

$$
v=v_{r e f}\left(\frac{h}{h_{r e f}}\right)^{\alpha}
$$


where $v$ is the wind speed at the wind turbine hub height $h$; $v_{r e f}$ is wind speed from the renewable resource data, measured at height $h_{r e f}$; and $\alpha$ is the wind shear coefficient, taken to be 0.143 . The wind turbine "power curve" is then defined based on the wind power equation:

$$
P_{t}=\frac{1}{2} C_{p} \rho A v^{3}
$$

where $P_{t}$ is the theoretical wind turbine power output; $C_{p}$ is the power coefficient; $\rho$ is the air density; $A$ is the turbine rotor swept area and $v$ is the wind speed at the rotor hub height. In practice, $C_{p}$ is a non-linear function of the turbine's tip speed ratio; however, in SCORES, it is assumed to be a constant value, derived from Equation (2) for the turbine's power output at rated wind speed $v_{\text {rated }}$.

The actual wind turbine power output $P$ is then calculated from $P_{t}$ as follows:

$$
P(v)=\left\{\begin{array}{ccc}
0 & \text { for } & v<v_{\text {cut-in }} \\
P_{t}(v) & \text { for } & v_{\text {cut-in }} \leq v<v_{\text {rated }} \\
P_{t}\left(v=v_{\text {rated }}\right) & \text { for } & v_{\text {rated }} \leq v<v_{\text {cut-out }} \\
0 & \text { for } & v \geq v_{\text {cut } \text { out }}
\end{array}\right.
$$

where $v_{\text {cut-in }}$ is the cut-in wind speed (at which the turbine begins outputting power); $v_{\text {rated }}$ is the rated wind speed (at which maximum power output is first achieved); and $v_{\text {cut-out }}$ is the cut-out wind speed (at which the turbine shuts down). The parameters $h, A$, $v_{\text {cut-in }}, v_{\text {rated }}$ and $v_{\text {cut-out }}$ are all input parameters that are defined based on the manufacturer specifications for the turbine being modelled. The details of the assumptions used for the offshore and onshore models in this study are shown in Table 1.

Table 1. Technology input data used for offshore and onshore wind turbines in this study.

\begin{tabular}{lll}
\hline & Offshore Wind Model [23] & Onshore Wind Model [24] \\
\hline Reference Turbine & AMSC SeaTitan & Envision E128 \\
Rated Power $P_{\text {rated }}(\mathrm{MW})$ & 10 & 3.6 \\
Hub height $h(\mathrm{~m})$ & 150 & 88 \\
Rotor swept area $A\left(\mathrm{~m}^{2}\right)$ & $\pi 95^{2}$ & $\pi 64^{2}$ \\
Cut-in wind speed $v_{\text {cut-in }}(\mathrm{m} / \mathrm{s})$ & 4 & 3 \\
Rated wind speed $v_{\text {rated }}(\mathrm{m} / \mathrm{s})$ & 11.5 & 11.5 \\
Cut-out wind speed $v_{\text {cut-out }}(\mathrm{m} / \mathrm{s})$ & 30 & 25 \\
\hline
\end{tabular}

\subsubsection{Solar Model}

The Solar Model converts the solar irradiance data to solar PV power output data. The hourly power output $P$ of a solar PV installation of area $A$, subject to radiation $D$, is calculated as follows:

$$
P=D A \eta
$$

where $\eta$ is a fixed efficiency parameter for the PV panel. Similarly, the installation area $A$ relates to its nominal maximum power output $C$ via a fixed area factor $a_{f}$ :

$$
A=C a_{f}
$$

The radiation seen by the PV installation, $D$, is derived from the global horizontal irradiation input data described in Section 2.2. The method used follows the equations set out by Duffie and Beckman [25], and is detailed in Appendix A. The method accounts for the panel location, tilt and orientation, as well as how diffuse the irradiation is. The key panel parameters used in this study are shown in Table 2. The PV nominal capacity is not defined as an input parameter, as it is varied depending on the total solar installed capacity that is modelled. 
Table 2. Technology input data used for solar PV in this study calculated from data in [26,27].

\begin{tabular}{cc}
\hline & Solar Model \\
\hline Panel efficiency $\eta(\%)$ & 17 \\
Panel area factor $\mathrm{a}_{\mathrm{f}}\left(\mathrm{m}^{2} / \mathrm{kW}\right)$ & 5.84 \\
Panel tilt angle $\beta\left(^{\circ}\right)$ & 22 \\
Panel azimuth angle $\gamma\left({ }^{\circ}\right)$ & 0 \\
\hline
\end{tabular}

\subsection{Storage Model}

\subsubsection{Storage Technology Parameters}

One or more storage technologies may be included in the model. All modelled storage technologies follow the same operating principles, but are differentiated by technology parameters, which may determine their preferred mode of operation. The storage technology parameters that are modelled in SCORES are shown in Table 3, with the values of those parameters that were used to model Li-ion batteries in this study.

Table 3. Technology parameters used for Li-ion batteries in this study.

\begin{tabular}{ll}
\hline & Li-Ion Batteries [28] \\
\hline Charging efficiency (\%) & 95 \\
Discharging efficiency (\%) & 95 \\
Self-discharge (\% per month) & 2 \\
Maximum charging rate (\% per hour) & 100 \\
Maximum discharging rate (\% per hour) & 100 \\
\hline
\end{tabular}

A nominal battery storage or power capacity is not defined as an input, as this is determined by the total installed capacity of batteries. However, the parameters shown in Table 3 are sufficient to determine the operating limits of the technology. For example, based on a maximum charging and discharging rates of $100 \%$ per hour, a battery with a nominal storage capacity of $20 \mathrm{MWh}$, would have a nominal power rating of $20 \mathrm{MW}$.

\subsubsection{Storage Operation for a Single Storage Technology}

The storage model is based on an hourly "surplus" profile $E_{S}$, which is defined as the total electricity generation minus the electricity demand:

$$
E_{S}=E_{G}-E_{D}
$$

where $E_{G}$ is the hourly generation profile, determined by the Generation Model, and $E_{D}$ is the hourly demand profile, a model input. $E_{S}$ may be positive in the case of a generation surplus, or negative in the case of a deficit.

The storage model assumes opportunistic storage operation: in the event of a generation surplus $\left(E_{S}>0\right)$, the storage is charged at the maximum available rate; meanwhile, in a generation deficit $\left(E_{S}<0\right)$, the storage is discharged at the maximum available rate. The maximum available charging or discharging rate is constrained by a number of variables:

- The total available surplus (or deficit) during the given time interval (the storage cannot continue charging if there is no more electricity available);

- The remaining storage capacity (the storage cannot continue charging if it is already full);

- The maximum charging or discharging rate of the technology (as defined in Table 3).

The remaining storage inventory is tracked across the simulation, and the charging and discharging efficiencies are accounted for as electricity is either put into storage or withdrawn. Additionally, the storage inventory is depleted in each interval based on the self-discharge rate defined in Table 3. Once the storage operation has been simulated for an entire time history, a new post-storage surplus profile will have been generated. Depending on the effectiveness of the storage technology, the new surplus profile may now 
be entirely positive, indicating that all generation deficits have been eliminated through storage. However, the post-storage surplus may still include negative values, indicating that there are time steps for which a generation deficit remains.

A "reliability" metric is used to measure the extent of remaining deficits. This metric is valuable for comparing the effectiveness of different generation and storage systems. Here we a metric previously used by Budischak et al. [29]: the percentage of the simulation time for which the demand was met, such that reliability is defined as:

$$
\text { reliability }(\%)=\frac{t_{\text {deficit }}}{t_{\text {total }}} \times 100
$$

where $t_{\text {deficit }}$ is the total number of timesteps where a deficit occurs (i.e., electricity demand exceeds supply, even after storage has been utilised), and $t_{\text {total }}$ is the total number of timesteps in the simulation. This metric describes the percentage of time intervals for which demand could be met entirely with renewable electricity and storage. Although this does not capture the magnitude of energy shortfalls, as the storage is assumed to operate opportunistically (rather to maximise this metric) there is no danger of the system purposefully missing demand where a shortfall is unavoidable.

It should be noted that this specific definition of "reliability" is concerned only with the renewable generators, storage, and demand profile included in the model. Any "missed reliability" under this definition simply indicates that additional flexibility may be required, such as dispatchable generation or demand-side response. In the remainder of this article, the term "reliability" will only be used as defined above.

\subsubsection{Multiple Storage Assets}

Different storage technology types can be modelled concurrently in SCORES, for example, to include both Li-ion batteries and hydrogen storage in the same system. The same opportunistic storage algorithm is used; however, a precedence order must also be chosen to determine which storage technology type is charged and discharged first. Future work will investigate more dynamic precedence setting in order to maximise the overall system benefit. In this study, only one storage technology type (Li-ion batteries) was modelled.

\subsection{Demand Data}

The relationship between renewable generation and electricity demand will dictate the required amount of energy storage. Electricity demand is partially determined by human behaviour, and thus dependent on the weather. This complicates the problem of estimating the reliability of renewable electricity systems because generation will also be strongly weather dependent. Here, we propose using historic demand alongside historic weather data, so that this relationship is accurately captured.

For this study, electricity data were obtained from Gridwatch [30], an API for accessing historic UK electricity demand. The demand is available at 5 min intervals; however, it was down-sampled to hourly resolution and missing points were forward-filled.

Figure 2 shows the resulting electricity demand profiles. As can be seen, there is significant variability across the year, with much larger electricity demands in winter. Demand is also much higher during the day than overnight, and with an early evening peak.

Although there are models of the future electricity profile (e.g., [31-33]) these take a sample-day approach. This approach is not appropriate for estimating system reliability because both demand and renewable generation can have rare long events that must be accounted for-e.g., a two-week period of low wind output. We believe the proposed method is the most robust available for quantifying the reliability of an electricity system.

The limitation of using historic demand data in this way is that future changes to the electricity demand profile are not included. Electrification of transport and heating are likely to both increase total electricity consumption, and change its diurnal and seasonal 
profiles. It would be possible to model these additional loads and then superimpose them onto historic demand data. This will be explored in future work.

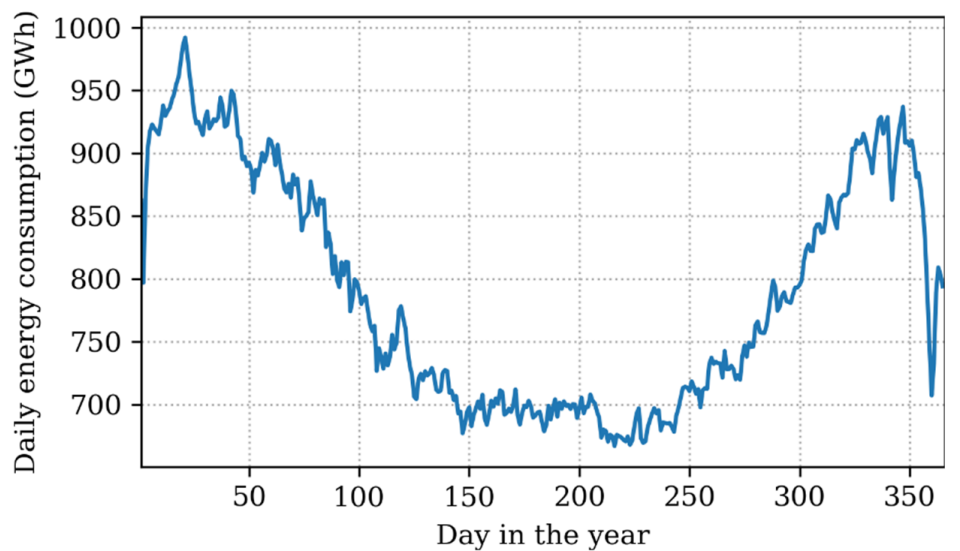

(a)

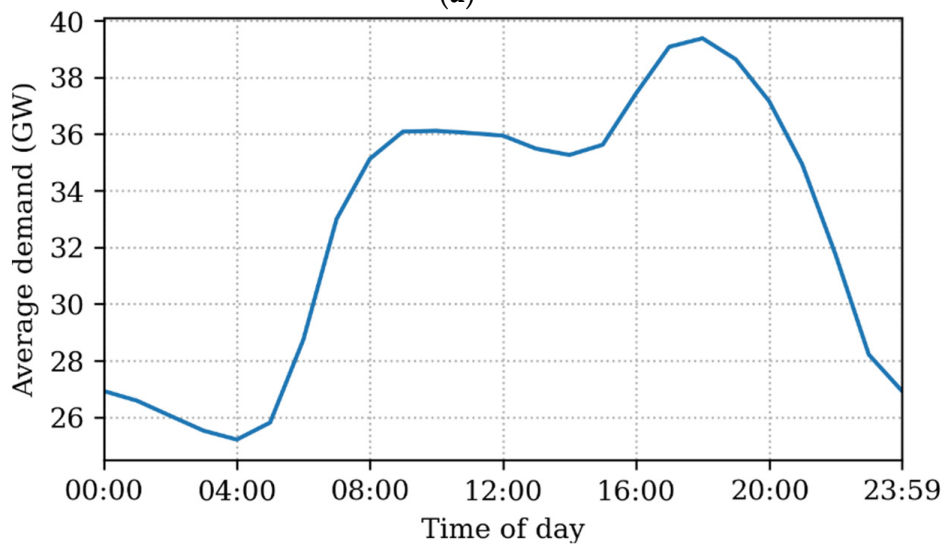

(b)

Figure 2. Illustration of the electricity demand data used in the simulations: (a) daily electricity consumption throughout the year; (b) electricity demand profile on the "average day".

\section{Results and Discussion}

This section presents results generated with the SCORES model. A case study of Great Britain and its territorial water is modelled, with electricity generation made up of offshore wind, onshore wind, and solar power aided by battery energy storage. Offshore wind, onshore wind, and solar power plants are assumed to be evenly distributed across the territory. For all results in this section, the system is simulated at an hourly time step, using historic electricity demand and weather data between the years 2013 and 2019 inclusive; therefore, a total of $61,344 \mathrm{~h}$ were simulated. These results analyse the effect of sizing the various aspects of the system on the resultant reliability factor as defined by Equation (7).

\subsection{Varying Installed Generation and Storage Capacity}

The reliability of a renewable electricity system may be increased by increasing either the total installed generation capacity or the total installed storage capacity. Increased generation means that the storage is used less frequently, so it is more likely to be available to discharge at times of shortfall. By contrast, increased storage capacity means that a larger percentage of generation surplus can be shifted to meet demand. Here, we investigate how the reliability of the electricity system changes as one increases either the installed generation capacity or storage. We assume a fixed ratio of renewable energy capacity of $40 \%$ offshore wind, 30\% onshore wind, and 30\% solar (percentages taken by nameplate capacity, not energy generation).

Figure 3 shows the variation in system reliability for a range of system generation and storage capacities. Note that the "reliability" is as defined in Equation (7); therefore, 
"missed" reliability does not necessarily represent a system failure, but suggests that further alternative flexibility provision (such as dispatchable power generation or demand-side response) would be required.

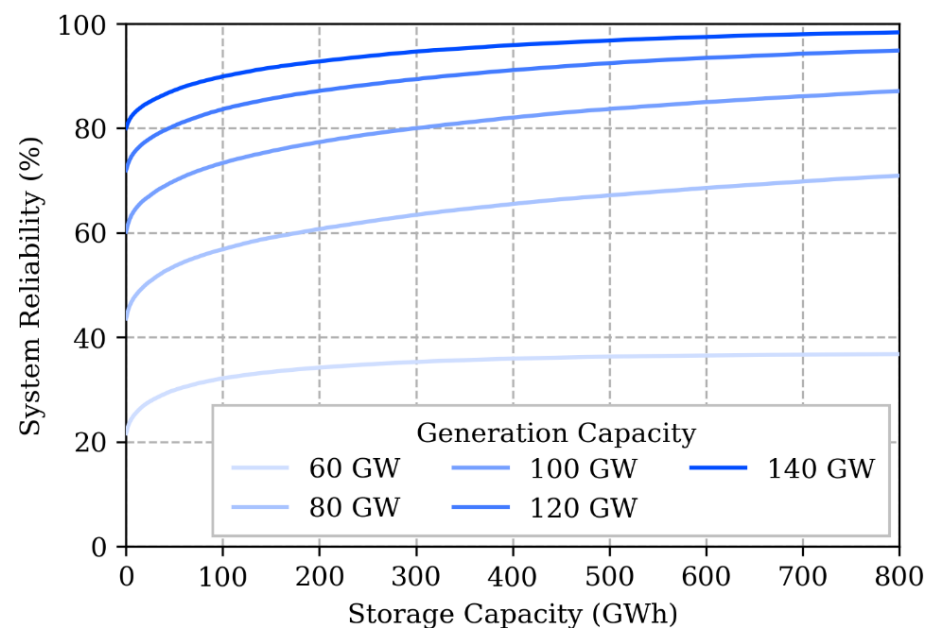

(a)

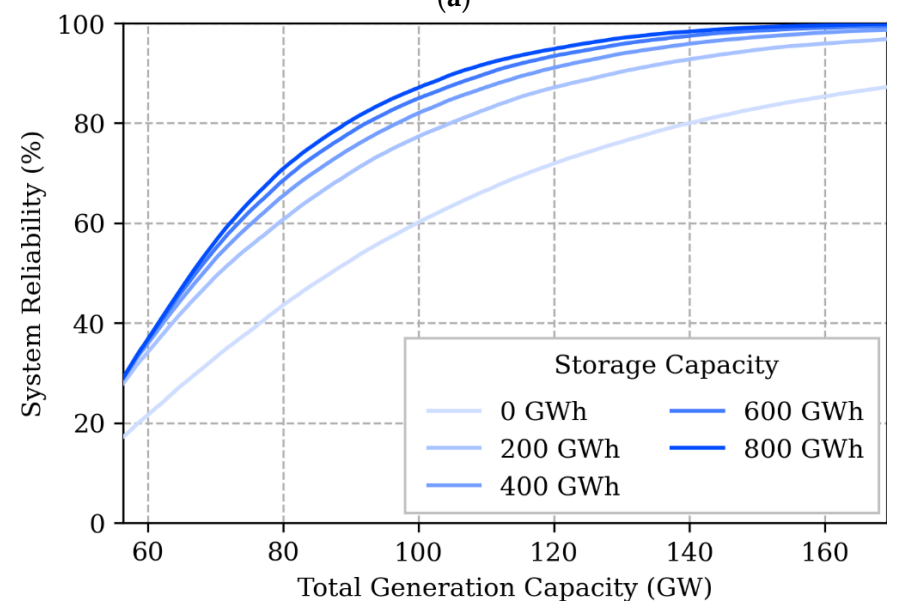

(b)

Figure 3. System reliability for a range of total system generation and storage capacities: (a) variation in system reliability with storage capacity, for five levels of generation capacity; (b) variation in system reliability with generation capacity, for five levels of storage capacity. Each system is made up of $40 \%$ offshore wind, $30 \%$ onshore wind and $30 \%$ solar PV.

Figure 3a shows five different total generation capacities, each with a range of storage capacities between $0 \mathrm{GWh}$ and $800 \mathrm{GWh}$. At very low levels of storage the marginal utility of additional storage is high; i.e., a small further increase results in a substantial increase in reliability. However, as the amount of storage increases the marginal utility decreases, and for each installed generation capacity, the achievable reliability plateaus. In the cases where there is sufficient energy to meet all demand, theoretically close to $100 \%$ reliability should be possible (start-up effects of the simulation may prevent $100 \%$ from being reached). However, the cost of achieving an extra unit of reliability may become prohibitively high.

Figure $3 \mathrm{~b}$ shows the variation in system reliability as the total generation capacity is increased from $55 \mathrm{GW}$ to $170 \mathrm{GW}$ for five levels of installed storage. Recall that generation capacity values are for total nameplate capacity rather than peak generation output (an important distinction as the peak output of the different renewables are unlikely to occur at the same time). For this range of values, total generation capacity has a more pronounced effect on reliability (although having energy storage significantly increases reliability).

Given the load factors of each renewable generator, the "average load factor" of the electricity generation system (with $40 \%$ offshore wind, $30 \%$ onshore wind and $30 \%$ solar) is 
$40 \%$; therefore, a $60 \mathrm{GW}$ system, for example, would only generate $24 \mathrm{GW}$ on average. By comparison, the average electricity demand in the scenario is around $33 \mathrm{GW}$. From this, we can see that even in a system with "perfect storage", a minimum generation capacity of around $83 \mathrm{GW}$ would be required in order to meet the $33 \mathrm{GW}$ "average demand" (thus achieving 100\% reliability). As the results in Figure 3 show, the storage system is nonperfect, so in fact system reliabilities remain well below $100 \%$ until generation capacity exceeds $100 \mathrm{GW}$, no matter how much storage is included.

\subsection{Varying Generation Mix}

As well as the total installed generation capacity, the relative sizes of the generation assets will influence system reliability. Table 4 shows some metrics for the hourly generation profiles of different generation technologies. The generator's load factor is calculated by dividing the average power output of the generator by its nameplate capacity, and for renewable generators, it is typically determined by the weather and the operating parameters of the generator. For example, solar generation has a significantly lower load factor than wind power due to the low number of sunlight hours per year. Load factor is important in this analysis because generators with higher load factors will generate more energy for a fixed installed generation capacity.

Table 4. Metrics for the time profiles of the offshore wind, onshore wind and solar generation profiles. Metrics include load factor, Pearson coefficient and correlation with demand, and correlation with the other generators.

\begin{tabular}{llll}
\hline & Offshore Wind & Onshore Wind & Solar \\
\hline Load Factor & $60.2 \%$ & $38.6 \%$ & $13.7 \%$ \\
Pearson coefficient with demand & 0.121 & 0.112 & 0.04 \\
Correlation with demand & $23.2 \%$ & $15.3 \%$ & $5.4 \%$ \\
Correlation with offshore wind & - & $28.1 \%$ & $6.9 \%$ \\
Correlation with onshore wind & $28.1 \%$ & - & $4.7 \%$ \\
Correlation with solar & $6.9 \%$ & $4.7 \%$ & - \\
\hline
\end{tabular}

The generator's Pearson coefficient and correlation with demand each give an indication of the degree to which the output of the generator matches the variations in demand. For example, as can be seen in Figure 2, the UK's electricity demand is lowest in the summer; meanwhile, solar power peaks in the summer, so seasonally the variation in solar power is not well aligned with demand. On the other hand, solar power is only available during the day, and the UK's demand is higher in the daytime. This is important because greater misalignment of generation and demand suggests an increased reliance on energy storage. Correlation is quantified by scaling each signal to vary between 1 and 0 and calculating the average product between the two signals, such that the minimum value is $0 \%$ and the maximum value is $100 \%$.

Finally, the correlation of each generator's output with the other generators gives an indication of how well "matched" different generators are. It might be expected that generators with a low correlation would be more complementary in an electricity system, although in practice, it will depend on wider system dynamics.

The load factor for offshore wind is by far the highest, as is the correlation with demand. As they result in a higher energy generated (so larger area under the power curve) we can expect signals with a higher load factor may have a larger correlation with any signal. It is important to note that the load factors and correlation alone cannot dictate what the best mix of generation technologies is, as the correlation coefficient does not dictate the required energy storage capacity - this also depends on how long the energy needs to be stored for.

Therefore, in the following subsections, we will examine how the system reliability changes for different ratios of the three generation technologies, with a fixed amount of energy storage. Given that the load factor varies with the power sources, we present two 
cases: one with a fixed total capacity, and one with a fixed total energy generation. This will help to distinguish between the effect of the high load factor and the effect of the generation profiles.

\subsection{Optimal Generation Mix with a Fixed Total Installed Capacity}

Figure 4 shows how the reliability of a system with $100 \mathrm{GW}$ of total generation and $300 \mathrm{GWh}$ of Li-ion battery storage changes with different relative installed capacities of the generator types.

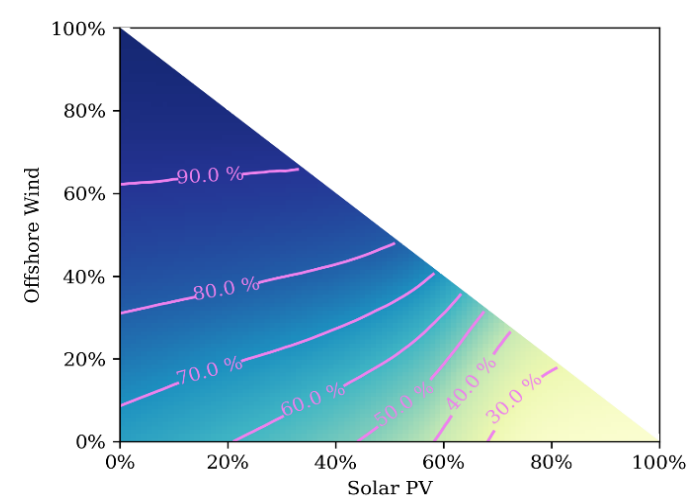

(a)

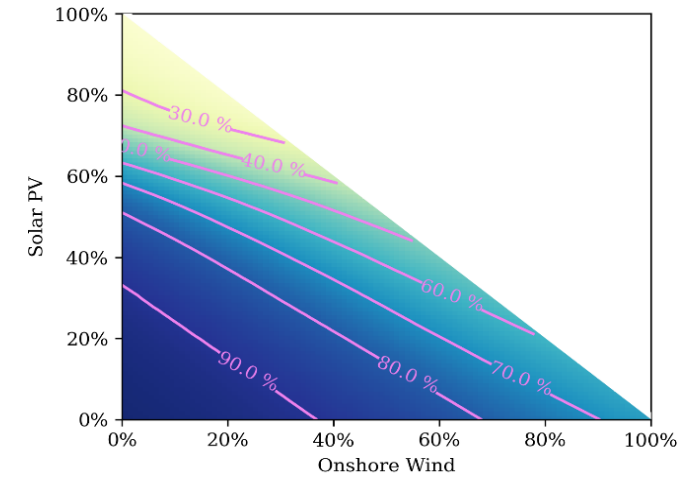

(b)

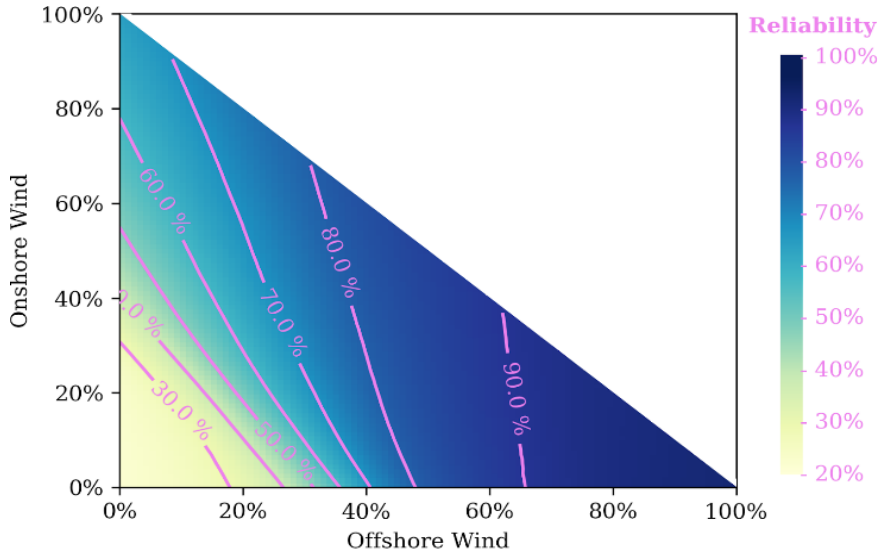

(c)

Figure 4. System reliability as a function of renewable capacity generation mix of solar PV, offshore wind and onshore wind with a total installed capacity of $100 \mathrm{GW}$ and a fixed storage installed capacity of 300 GWh. Graph (a) shows reliability of mixtures of offshore wind and solar PV, Graph (b) shows reliability with mixtures of solar PV and onshore wind and Graph (c) shows reliability with mixtures of onshore wind and offshore wind.

The top-left Figure 4a shows the percentage of total installed capacity provided by onshore wind on the x-axis, and the percentage provided by solar PV on the y-axis. The remaining capacity (summing to $100 \%$ ) is provided by offshore wind. The other two Figure $4 b, c$ shows the same generator types but assigned to different axes so that the interplay between each of the generator types can be seen. Only the bottom triangle is shaded in each case as the sum of the contribution from each generator types cannot exceed $100 \%$. Contour lines show lines of constant reliability, such that the generation mixes along the line will all have the same system reliability. It is interesting to consider the subset of generation mixes which create the same overall system reliability, because there may be political or economic considerations which favour one technology over the other.

The highest levels of reliability are found with a predominately offshore wind mix, which is likely caused because offshore wind has the highest load factor of the three generator types. A high penetration of solar power gives a low reliability regardless of the 
remaining mix between offshore and onshore wind. At high levels of offshore wind, the $90 \%$ contour is almost parallel to the y-axis-demonstrating that the reliability is almost the same regardless of the remaining make-up on onshore wind and solar. The contours show that the highest reliability levels are seen at, and close to, $100 \%$ offshore wind.

\subsection{Optimal Generation Mix with a Fixed Annual Generation}

Given that the total generation capacity is fixed at $100 \mathrm{GW}$ in the above example, there is a distortion towards the generation technologies with the higher load factors. As offshore wind has the highest load factor, a larger percentage of offshore wind means that the total energy generation is higher. To compare how the generation mix aligns with the demand profile, we can instead fix the total energy generation.

Figure 5 shows plots with a fixed energy generation of $350.4 \mathrm{TWh} /$ year, which is equivalent to $100 \mathrm{GW}$ of generation with a $40 \%$ load factor. In this case, the range of reliability is much smaller, demonstrating that the quantity of energy had a large effect on the previous results. Whereas in the previous example, the contours centred around the $100 \%$ offshore wind point, here, the optimal reliability occurs at around $75 \%$ offshore wind, $25 \%$ solar.

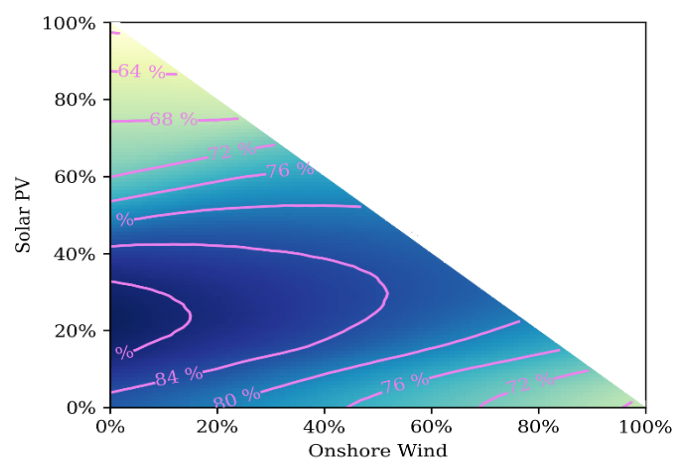

(a)

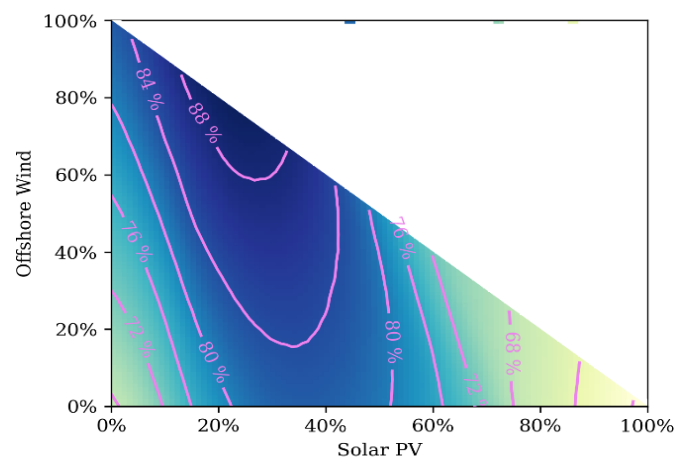

(b)

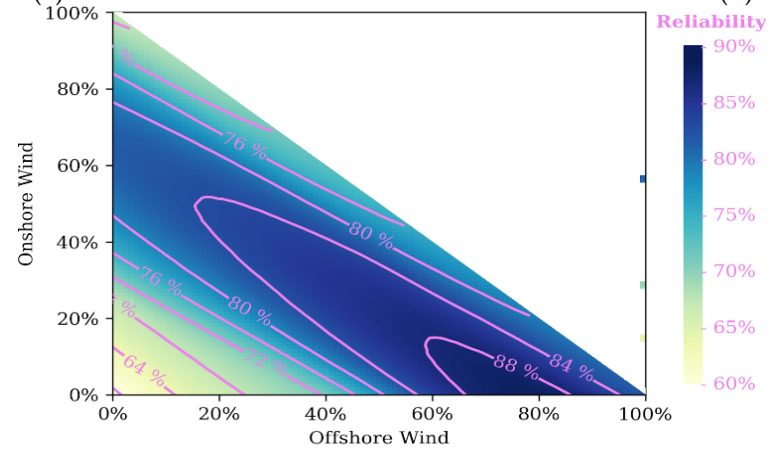

(c)

Figure 5. System reliability as a function of renewable energy generation mix of solar PV, offshore wind and onshore wind with a fixed annual generation of $350 \mathrm{TWh} / \mathrm{y}$ and a fixed storage installed capacity of $300 \mathrm{GWh}$. Graph (a) shows reliability of mixtures of offshore wind and solar PV, Graph (b) shows reliability with mixtures of solar PV and onshore wind and Graph (c) shows reliability with mixtures of onshore wind and offshore wind.

The dominance of offshore wind is likely because it has the highest correlation with demand (as shown in Table 4). Solar power is likely chosen because it complements the offshore wind, meaning that the solar is likely to be high when the offshore wind is low. This can also be seen from the correlation values: solar and offshore wind have less than a $7 \%$ correlation. There is little role for onshore wind, because it is more strongly correlated with offshore wind ( $28 \%)$, so compared to solar, it would be less effective at filling in the shortfalls of offshore wind. 
To further understand why the reliability varies this way with generator mix, it is useful to look at how the storage is used. Figure 6 shows a scatter plot of the reliability of a system versus the average number of consecutive hours for which the storage is fully charged. This gives an indication of how long energy is generally stored for, as while the storage is fully charged, it is not being used. The systems were chosen using the same assumptions as in Figure 5. The colour of each marker signifies the relative contribution of each generation technology to the total energy generation; for example, fully blue markers denote a $100 \%$ offshore wind powered system.

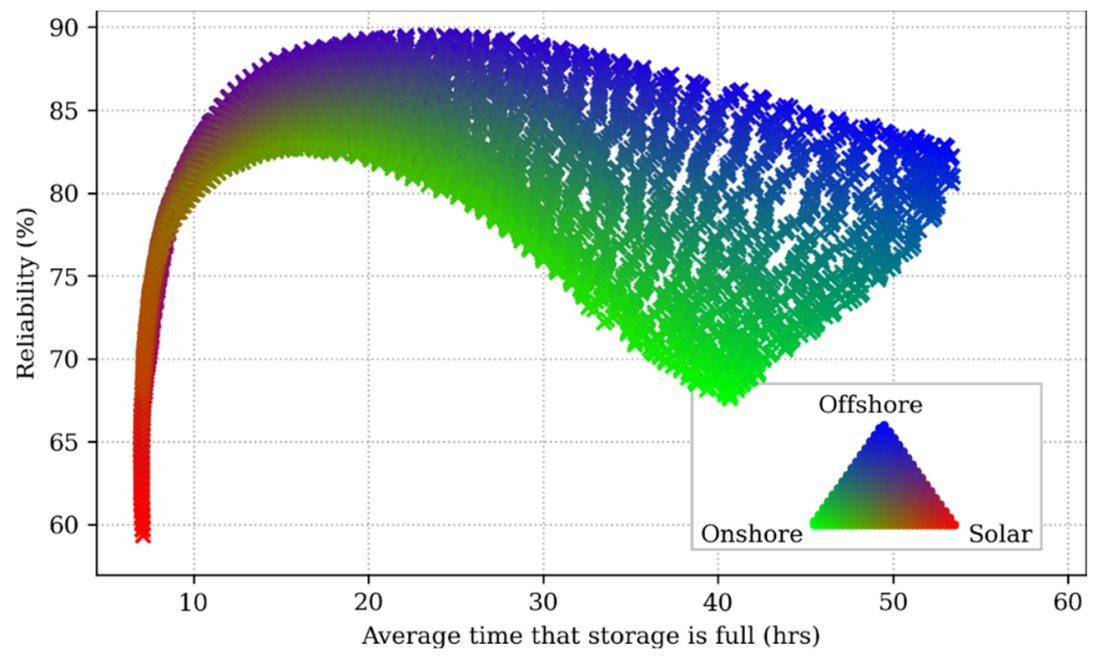

Figure 6. A scatter plot showing the reliability of different system designs against the average number of consecutive hours for which the energy storage was fully charged. Each system design has an annual generation of $350 \mathrm{TWh} / \mathrm{y}$ and $300 \mathrm{GWh}$ of storage. The colour of the markers indicates relative contribution of each generation technology to the total annual energy generation.

The system designs that are most reliant on solar power have the shortest durations for which the storage is fully charged, in the range of 5 to $16 \mathrm{~h}$. Clearly, this storage operation is driven by the day/night cycle of solar power. Meanwhile wind-based systems have much longer full-storage durations on average, indicating that the storage is used less frequently in those systems. The highest reliability systems have average full-storage durations of around $23 \mathrm{~h}$, whilst for some systems, this is in excess of $50 \mathrm{~h}$. These long storage durations may present challenges in finding a viable economic case for the storage when it is used so infrequently. However, they also show the opportunity for suitable long-duration storage technologies, with large capacity and low self-discharge.

\section{Summary and Conclusions}

In this paper, we developed a model to quantify how the reliability of renewable electricity generation changes with battery energy storage, given the geographic location. Separate models were developed for offshore wind, onshore wind, and solar power, which use hourly wind speed and solar irradiance data to estimate generation output. As a case study, we considered the reliability with which the UK's electricity demand could be met with renewable generation. First, we considered a fixed capacity generation mix of $40 \%$ offshore wind, $30 \%$ onshore wind, 30\% solar and investigate how the sizing of total generation and storage affects the reliability of the system. We showed that introducing storage to an electricity system significantly increases its reliability, but as the total level of storage increases, the marginal benefit of further storage quickly diminishes.

Second, we considered how the mix of the generation technologies affects the reliability of the system. We found that, when capacity is held constant, an entirely offshore wind mix is the most reliable, but this was largely because the load factor for offshore wind is much 
higher than the other two sources. When energy generation was held constant, the most reliable mix was approximately three-quarters offshore wind and one-quarter solar power.

Finally, we explored how the storage is used in systems with different generation mixes. We showed that high-solar systems use shorter duration storage, but the most reliable systems have storage durations greater $20 \mathrm{~h}$. Given that the economic viability of energy storage often requires a high usage rate, incentivisation methods or alternative storage technologies need to be investigated.

The results of the case study provide some insights into the design of a low-carbon electricity system in the UK. With appropriate amounts of energy storage, electricity demand can be met with a high degree of reliability using only renewable generation technologies. In the UK, when total generated energy or generated power is constrained, the most reliable systems are dominated by offshore wind. When total generated energy is constrained, adding solar power to the offshore wind increases reliability due to its complementary nature to offshore wind.

Additionally, more general conclusions about sizing a renewable electricity system can be formed. In this study, we developed the SCORES model and demonstrated how it can be used to explore the interactions of different electricity generation technologies, storage, and electricity demand. The case study showed that neither correlation nor load factor were accurate predictors for the resulting reliability, meaning that hourly simulations are necessary.

It is nontrivial to optimally size a renewable electricity system because there are at least four variables to consider: the quantity of each renewable resource and the amount of energy storage. Here, we demonstrated example results that can be visualised by fixing certain quantities, such as the total installed storage capacity. In practice, system planners will have their own constraints and we hope that our open source model will allow them to explore potential future system designs.

This study has focused on system reliability as the key metric, but with future work, we plan to expand SCORES to include optimisation of system cost, which will enable us to investigate the trade-offs between cost and reliability. By including additional storage technologies with different performance parameters, we also plan to explore the relative merits of different generation and storage technologies in more detail.

Author Contributions: Conceptualisation, C.C. and I.L.; methodology, C.C., D.P. and C.Q.; software, C.C.; validation, C.C., C.Q. and D.P.; formal analysis, N.M.; investigation, N.M.; resources, N.M.; data curation, C.Q.; writing—original draft preparation, C.Q., C.C. and I.L.; writing—review and editing, C.Q.; visualisation, C.C.; supervision, I.L. All authors have read and agreed to the published version of the manuscript.

Funding: This research received no external funding.

Institutional Review Board Statement: Not applicable.

Informed Consent Statement: Not applicable.

Data Availability Statement: All original data can be provided by request from the authors. The model and usage instructions are publicly available at: https://github.com/constancecrozier/ SCORES (accessed on 30 December 2021).

Conflicts of Interest: The authors declare no conflict of interest.

\section{Appendix A}

The following equations are used convert the actual global horizontal solar irradiation data $I$ into the radiation seen by a solar panel at a given location and orientation. The method also accounts for the atmospheric "clearness", to determine extent to which the irradiation seen by the panel is "direct" or "diffuse". This is achieved by comparing the actual solar irradiance data $I$ to the expected extraterrestrial radiation for the day and time. The method has been derived from by Duffie and Beckman [25] and is as follows. 
First, the solar declination angle $\delta$ is approximated for each day $n$ of a given year:

$$
\delta=23.45 \sin \left(\frac{360(384+n)}{365}\right)
$$

The hourly angle of incidence $\theta$ of direct radiation on the solar panel can then be calculated:

$$
\begin{aligned}
\cos (\theta)=\sin (\delta) & \sin (\phi) \cos (\beta)-\sin (\delta) \cos (\phi) \sin (\beta) \cos (\delta) \\
& +\cos (\delta) \cos (\phi) \cos (\beta) \cos (\omega) \\
& +\cos (\delta) \sin (\phi) \sin (\beta) \cos (\gamma) \cos (\omega) \\
& +\cos (\delta) \sin (\beta) \sin (\gamma) \sin (\omega)
\end{aligned}
$$

where $\delta$ is the solar declination angle; $\phi$ is the site's latitude; $\beta$ is the panel tilt angle; $\gamma$ is the panel azimuth angle (with zero equalling due south); and $\omega$ is the hour angle (angle of the sun relative to the meridian for each hour of the day).

The extraterrestrial radiation acting on a surface perpendicular to the sun is defined based on the solar constant $G_{S C}$, which is assumed in the SCORES model to be $1.367 \mathrm{~kW} / \mathrm{m}^{2}$ [25]. However, as the earth's distance from the sun varies throughout the year, this also affects the level of extraterrestrial radiation seen by the earth. Therefore, an adjusted solar value $G_{o n}$ for each day of the year $n$ is calculated:

$$
G_{o n}=G_{s C}\left(1+0.033 \cos \left(\frac{360 n}{365}\right)\right)
$$

This is then used to calculate the instantaneous horizontal extraterrestrial radiation $G_{0}$, adjusting for the solar declination, hour angle, and site latitude:

$$
G_{0}=G_{o n}(\cos (\phi) \cos (\delta) \cos (\omega)+\sin (\phi) \sin (\delta))
$$

However, as the actual solar irradiation data $I$ are provided on an hourly basis, Equation (A4) must be integrated over one hour to give the hourly horizontal extraterrestrial radiation $I_{0}$ :

$$
I_{0}=\left(\frac{12}{\pi}\right) G_{o n}\left(\cos (\phi) \cos (\delta)(\sin (\omega+7.5)-\sin (\omega-7.5))+\frac{15 \pi}{180}(\sin (\phi) \sin (\delta))\right)
$$

Based on this, an hourly "clearness index" $k_{T}$ can be calculated, representing the relative size of the actual horizontal irradiation $I$, compared to the extraterrestrial horizontal radiation $I_{0}$ :

$$
k_{T}=\frac{I}{I_{0}}
$$

The fraction of diffuse radiation is then calculated, using the empirical relationship proposed by Erbs et al.:

$$
\varepsilon=\left\{\begin{array}{cc}
1.0-0.09 k_{T} & \text { for } k_{T} \leq 0.22 \\
0.9511-0.1604 k_{T}+4.388 k_{T}^{2}-16.638 k_{T}^{3}+12.336 k_{T}{ }^{4} & \text { for } 0.22<k_{T} \leq 0.80 \\
0.165 & \text { for } k_{T}>0.8
\end{array}\right.
$$

Finally, the "direct" and "diffuse" $\left(D_{d}\right)$ components of the actual irradiation data, incident on the panel, can be calculated. The "direct", or "beam" radiation $D_{b}$ accounts for the angle at which the beam radiation meets the panel as follows:

$$
D_{b}=I(1-\varepsilon)\left(\frac{\cos (\theta)}{\cos (\phi) \cos (\delta) \cos (\omega)+\sin (\phi) \sin (\delta)}\right)
$$


Meanwhile the "diffuse" radiation $D_{d}$ accounts for the fraction of sky that is seen by the panel, given that it is tilted at angle $\theta$ :

$$
D_{d}=I \varepsilon\left(\frac{1+\cos (\theta)}{2}\right)
$$

The total hourly panel irradiation is then the sum of these components:

$$
D=D_{b}+D_{d}
$$

\section{References}

1. Davis, S.J.; Lewis, N.S.; Shaner, M.; Aggarwal, S.; Arent, D.; Azevedo, I.L.; Benson, S.M.; Bradley, T.; Brouwer, J.; Chiang, Y.-M.; et al. Net-zero emissions energy systems. Science 2018, 360, 1419. [CrossRef] [PubMed]

2. Vivid Economics and Imperial College London. Accelerated Electrification and the GB Electricity System. 2019. Available online: www.theccc.org.uk/wp-content/uploads/2019/05/CCC-Accelerated-Electrification-Vivid-Economics-Imperial-1.pdf (accessed on 10 December 2021).

3. Baruah, P.J.; Eyre, N.; Qadrdan, M.; Chaudry, M.; Blainey, S.; Hall, S.; Jenkins, J.W.; Tran, M. Energy system impacts from heat and transport electrification. Proc. Inst. Civ. Eng. Energy 2014, 167, 139-151. [CrossRef]

4. International Energy Agency. Projected Costs of Generating Electricity. 2020. Available online: www.iea.org/reports/projectedcosts-of-generating-electricity-2020 (accessed on 12 October 2021).

5. Jacobson, M.; Delucchi, M.; Bauer, Z.; Goodman, S.; Chapman, W.; Cameron, M. 100\% Clean and renewable wind, water, and sunlight all-sector energy Roadmaps for 139 countries of the world. Joule 2017, 1, 108-121. [CrossRef]

6. Lund, H.; Mathiesen, B. Energy system analysis of 100\% renewable energy systems-The case of Denmark in years 2030 and 2050. Energy 2009, 34, 524-531. [CrossRef]

7. Elliston, B.; Diesendorf, M.; Macgill, I. Simulations of Scenarios with 100\% Renewable Electricity in the Australian National Electricity Market. University of New South Wales. 2012. Available online: www.ceem.unsw.edu.au/sites/default/files/ documents/simulations.pdf (accessed on 12 October 2021).

8. Connolly, D.; Lund, H.; Mathiesen, B.; Leahy, M. The first step towards a 100\% renewable energy system for Ireland. Appl. Energy 2011, 88, 502-507. [CrossRef]

9. Department for Business, Energy and Industrial Strategy. Plans Unveiled to Decarbonise UK Power System by 2035, Press Release. 2021. Available online: www.gov.uk/government/news/plans-unveiled-to-decarbonise-uk-power-system-by-2035 (accessed on 10 December 2021).

10. Climate Change Committee. The Sixth Carbon Budget: The UK's Path to Net Zero. 2020. Available online: www.theccc.org.uk/ wp-content/uploads/2020/12/The-Sixth-Carbon-Budget-The-UKs-path-to-Net-Zero.pdf (accessed on 12 October 2021).

11. Ahmed, S.D.; Al-Ismail, F.S.M.; Shafiullah, M.; Al-Sulaiman, F.A.; El-Amin, I.M. Grid Integration Challenges of Wind Energy: A Review. IEEE Access 2020, 8, 10857-10878. [CrossRef]

12. Newbery, D.; Pollitt, M.G.; Ritz, R.A.; Strielkowski, W. Market design for a high-renewables European electricity system. Renew. Sustain. Energy Rev. 2018, 91, 695-707. [CrossRef]

13. Johnson, S.; Rhodes, J.; Webber, M. Understanding the impact of non-synchronous wind and solar generation on grid stability and identifying mitigation pathways. Appl. Energy 2020, 262, 114492. [CrossRef]

14. DNV GL. Future Technology Improvements: Potential to Improve Load Factor of Offshore Wind Farms in the UK to 2035. 2019. Available online: www.gov.uk/government/publications/potential-to-improve-load-factor-of-offshore-wind-farms-in-the-ukto-2035 (accessed on 10 December 2021).

15. Shubbak, H.M. Advances in solar photovoltaics: Technology review and patent trends. Renew. Sustain. Energy Rev. 2019, 115, 109383. [CrossRef]

16. Pfenninger, S.; Staffell, I. Long-term patterns of European PV output using 30 years of validated hourly reanalysis and satellite data. Energy 2016, 114, 1251-1265. [CrossRef]

17. Staffell, I.; Pfenninger, S. Using Bias-Corrected Reanalysis to Simulate Current and Future Wind Power Output. Energy 2016, 114, 1224-1239. [CrossRef]

18. Daly, H.E.; Fais, B. UK TIMES Model Overview. 2014. Available online: www.ucl.ac.uk/energy-models/models/uk-times (accessed on 10 December 2021).

19. Strbac, G.; Pudjianto, D.; Aunedi, M.; Djapic, P.; Teng, F.; Zhang, X.; Ameli, H.; Moreira, R.; Brandon, N. Role and value of flexibility in facilitating cost-effective energy system decarbonization. Prog. Energy 2020, 2, 042001. [CrossRef]

20. NASA. Modern-Era Retrospective AnalWysis for Research and Applications, Version 2. Available online: https://gmao.gsfc.nasa. gov/reanalysis/MERRA-2/ (accessed on 28 September 2021).

21. Wilson, C.; Webster, S.; Vosper, S.; Clark, P.; Brown, A.; Murkin, P.; Leonard-Williams, A.; Butcher, T.; Harrison, R. The met office virtual met mast. Eur. Wind Energy Conf. Exhib. 2010, 4, 2683-2713.

22. Met Office. Observed Data from Weather Stations and Rain Gauges. Available online: https://www.metoffice.gov.uk/services/ data/business-data\#Historical\%20and\%20current\%20weather\%20data (accessed on 28 September 2021). 
23. AMSC. SeaTitan 10 MW Wind Turbine Data Sheet. Available online: https://amsc.com/wp-content/uploads/wt10000_DS_A4_0 212.pdf (accessed on 12 October 2021).

24. Wind-turbine-models.com. Envision E128-3.6MW PP 2B. Available online: https://en.wind-turbine-models.com/turbines/284envision-e128-3.6mw-pp-2b\#datasheet (accessed on 12 October 2021).

25. Duffie, J.A.; Beckman, W.A. Solar Engineering of Thermal Processes, 4th ed.; Wiley: Hoboken, NJ, USA, 2013.

26. Palmer, D.; Koubli, E.; Betts, T.; Gottschalg, R. The UK Solar Farm Fleet: A Challenge for the National Grid? Energies 2017, 10, 1220. [CrossRef]

27. Fraunhofer Institute for Solar Energy Systems. Photovoltaics Report. 2021. Available online: www.ise.fraunhofer.de/content/ dam/ise/de/documents/publications/studies/Photovoltaics-Report.pdf (accessed on 28 September 2021).

28. Cole, W.; Frazier, A. Cost Projections for Utility-Scale Battery Storage. National Renewable Energy Laboratory. 2019. Available online: www.nrel.gov/docs/fy19osti/73222.pdf (accessed on 12 October 2021).

29. Budischak, C.; Sewell, D.; Thomson, H.; Mach, L.; Veron, D.E.; Kempton, W. Cost-minimized combinations of wind power, solar power and electrochemical storage, powering the grid up to $99.9 \%$ of the time. J. Power Sources 2013, 225, 60-74. [CrossRef]

30. Gridwatch. 2021. Available online: www.gridwatch.templar.co.uk (accessed on 12 October 2021).

31. UK-TIMES Model. Available online: https://www.ucl.ac.uk/energy-models/models/uk-times (accessed on 28 September 2021).

32. National Grid. National Grid Future Energy Scenarios (FES) 2021. Available online: https:/ /www.nationalgrideso.com/futureenergy / future-energy-scenarios / fes-2021/documents (accessed on 28 September 2021).

33. Department for Business, Energy and Industrial Strategy (BEIS). The Dynamic Dispatch Model: A Fully Integrated Power Market Model. Available online: https:/ / www.gov.uk/government/statistics/the-dynamic-dispatch-model-a-fully-integrated-powermarket-model (accessed on 28 September 2021). 